\title{
Non-Mendelian transmission of apomixis in maize-Tripsacum hybrids caused by a transmission ratio distortion
}

\author{
DANIEL GRIMANELLI* + , OLIVIER LEBLANC $\dagger$, ELSA ESPINOSA $\dagger$, ENRICO PEROTTI \\ DIEGO GONZÁLEZ DE LEON $+\&$ YVES SAVIDAN $\dagger$ \\ †ORSTOM, Institut Français de Recherche Scientifique pour le Développement en Coopération and †CIMMYT, \\ International Maize and Wheat Improvement Center, CIMMYT Applied Technology Biocenter, Apdo 6-641, 06600 \\ Mexico DF, Mexico
}

\begin{abstract}
Apomixis is a mode of asexual reproduction through seeds. The apomictic process bypasses both meiosis and egg cell fertilization, producing offspring that are exact genetic replicas of the mother plant. In the Tripsacum agamic complex, all polyploids reproduce through the diplosporous type of apomixis, and diploids are sexual. In this paper, molecular markers linked with diplospory were used to analyse various generations of maize-Tripsacum hybrids and backcross derivatives and to derive a model for the inheritance of diplosporous reproduction. The results suggest that the gene or genes controlling apomixis in Tripsacum are linked with a segregation distorter-type system promoting the elimination of the apomixis alleles when transmitted through haploid gametes. Hence, this model offers an explanation of the relationship between apomixis and polyploidy. The evolutionary importance of this mechanism, which protects the diploid level from being invaded by apomixis, is discussed.
\end{abstract}

Keywords: agamic complex, apomixis, evolution, meiotic drive, Tripsacum.

\section{Introduction}

Asexual reproduction has been shown to present strong selective advantages in many circumstances (Maynard Smith, 1978; Marshall \& Brown, 1981). However, amphimixis, that is a life cycle with alternating syngamy and meiosis, is strikingly predominant over the various forms of asexual reproduction. Therefore, much attention has been devoted to identifying counterbalancing selective advantages that could account for the near-universality of amphimixis (for a classification of the various hypotheses, see Kondrashov, 1993).

Apomixis, asexual reproduction through seeds (Nogler, 1984a), is one of the various forms of asexual reproduction and is a common mode of reproduction in at least 300 species belonging to 35 higher plant families (Asker \& Jerling, 1992). The apomictic process bypasses both meiosis and egg cell fertilization, producing offspring that are exact genetic replicas of the mother plant.

*Correspondence: ORSTOM-CIMMYT, Apdo 6-641, 06600 Mexico DF, Mexico. E-mail: dgrimanelli@cimmyt.mx
When considering the conflict between sexual and asexual reproduction, apomixis appears to be of particular interest for at least two reasons. First, segregation analyses have demonstrated that apomixis is probably inherited as one Mendelian factor dominant over sexuality (Savidan, 1982; Nogler, 1984b; Leblanc et al., 1995a). Secondly, agamic complexes (after Babcock \& Stebbins, 1938) seem to offer a situation in which no selective advantages of amphimixis counterbalance the propagation of asexual genotypes; the coexistence of both modes of reproduction is solely realized through separation of the apomictic and sexual pools at different ploidy levels (de Wet, 1968; Savidan \& Pernès, 1982; Asker \& Jerling, 1992). Except for rare exceptions, diploid genotypes in agamic complexes are sexual, whereas apomixis is found at higher ploidy levels (Asker \& Jerling, 1992). The need for such separation is in agreement with the existing models; these predict that, when in competition at the same ploidy level and under a one dominant gene hypothesis, apomixis spreads to fixation and sexuality disappears (Pernès, 1972; Maynard Smith, 1978; Marshall \& Brown, 1981). 
However, gene flow between the diploid sexuals and polyploid apomicts is possible through diploidtetraploid-polyhaploid cycles (de Wet, 1968; Savidan \& Pernès, 1982). Potentially, then, the alleles controlling the switch to an apomictic mode of reproduction might be recovered at the diploid level. Hence, it has been inferred that some kind of mechanism protects the diploid level from being invaded by apomixis. Little is known about such mechanisms, but two hypotheses have been presented. The first one assumes that the allele or alleles responsible for apomictic development are not transmitted through haploid gametes (Nogler, 1982). Therefore, apomixis would not be recovered in diploid plants. The second one proposes a dosage effect by which apomixis is not expressed in diploids, although the corresponding alleles may be transmitted (Mogie, 1988; Noirot, 1993). According to Mogie (1988), several copies of the gene(s) are required for normal apomictic development, and the 'sexual allele' is needed for the viable development of the embryo. In quite the reverse hypothesis, Noirot (1993) proposed that the 'apomictic allele' must be in a ratio of 0.25 or less to be functional.

Polyploids in the genus Tripsacum reproduce through the diplosporous type of apomixis, whereas diploids are sexual. Diplospory in Tripsacum results from meiotic failure of the megasporocytes, which develop directly into mature unreduced female gametophytes through three or more mitoses. It is a facultative phenomenon, by which apomictic plants produce embryos both asexually (apomeiotic embryos) and sexually (meiotic embryos) (Leblanc et al., 1995b). In an attempt to transfer apomixis to maize (Zea mays L.) from Tripsacum, which is the closest apomictic wild relative of Zea, we reported recently the identification of molecular markers linked with the diplosporous mode of reproduction (Leblanc et al., 1995a). These markers provide direct access to genotypical information, and thus allow the study of the segregation of the segment controlling apomixis regardless of its expression. They can, therefore, be used as a powerful tool to discriminate between the hypotheses on the transmission of apomixis.

In this paper, various generations of maize-Tripsacum hybrids and backcross derivatives have been analysed both for the phenotypical expression of the apomictic mode of reproduction and for the transmission of the chromosomal segment carrying the apomictic gene(s), as revealed by specific molecular markers. The data reported here tend to demonstrate that the gene or genes controlling apomixis are not inherited through haploid gametes, rather than not expressed in diploids. Based on these data, we propose a model for the genetic control of this segregation distortion.

\section{Materials and methods}

\section{Plant materials}

The plant material used in this study has been described previously (Leblanc, 1995; Leblanc et al., 1995a). To summarize, an $F_{1}$ population was derived from hybridization between a maize plant $(2 n=2 \mathrm{x}=20)$ from CIMMYT population 34 as the pistillate parent and CIMMYT Tripsacum dactyloides (L.) L. accession 65-1234, an apomictic tetraploid $(2 n=4 \mathrm{x}=72)$ from Everglades (FL, USA) as the male parent. The hybrids recovered were $2 n=46$ combining 36 chromosomes from the Tripsacum parent and 10 from the maize parent $(10 \mathrm{Mz}+36 \mathrm{Td})$. They were male-sterile and only partially femalefertile. The population was segregating 1:1 for mode of reproduction, diplospory vs. meiosis, and served to identify molecular markers linked to the apomictic mode of reproduction (Leblanc et al., 1995a). Backcross (BC) derivatives were obtained from $\mathrm{BC}_{1}$ to $\mathrm{BC}_{4}$ by pollinating one of the apomictic $\mathrm{F}_{1}$ plants with a maize hybrid (CML $62 \times$ CML 135, CIMMYT lines). Because of male sterility affecting the $F_{1}$ hybrids and their derivatives, backcrosses were performed using maize as the male. The crossing scheme is shown in Fig. 1.

Following the nomenclature proposed by Harlan $\&$ de Wet (1975), progeny from facultative apomictic materials may comprise four types: (i) ' $2 n+0$ ' maternal offspring through apomixis, i.e. resulting from failure of both meiosis and fertilization; (ii) ' $2 n+n$ ' off-types, resulting from failure of meiosis and egg cell fertilization; (iii) ' $n+n$ ' off-types through sexuality (meiosis and fertilization); and (iv) ' $n+0$ ' polyhaploid off-types through parthenogenetic development of the reduced egg cell.

Progeny testing was used to discriminate between sexual and apomictic reproduction on the basis of modifications in chromosome numbers from the mother plant to the offspring. The proportions of the four classes of progenies described above, as estimated through chromosome counts, allow a clear distinction between sexual reproduction, producing exclusively $n+n$ progenies, and apomictic reproduction, in which the four types are represented in variable proportions. In some cases, analysis of callose deposition during megasporogenesis (sucroseaniline blue clearing procedure combined with epifluorescence microscopy), a reliable indicator of 
meiosis, was used for cytoembryological determination of modes of reproduction (Leblanc et al., 1995b).

At each generation, the apomictic mode of reproduction was used to amplify the original genotypes in order to generate very large progenies. In this amplification process, using maize as the male parent, off-types are generated. The predominant apomictically derived clones are themselves backcrossed recurrently with maize, again producing apomictic progenies and off-types. Hence, the $\mathrm{BC}_{1}$ generation comprised the original genotype and all the plants that were derived from this genotype through $2 n+0$ apomictic reproduction. In this process, only the plants that differed genetically from the mother plant $(2 n+n, n+n$ and $n+0$ off-types) represented the next generation.

\section{Chromosomal analyses}

Flow cytometry was used to estimate chromosome numbers. Leaf samples were prepared according to Galbraith et al. (1983) and analysed using a Partec CA-II cytometer (Partec, Münster, Germany). More

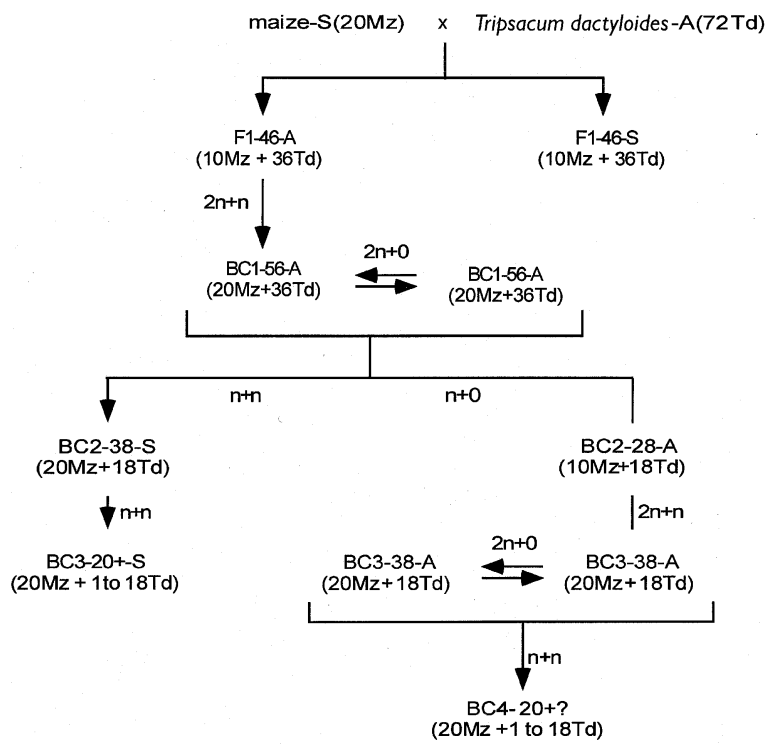

Fig. 1 Part of the crossing scheme, showing the maizeTripsacum hybrids and backcross derivatives used in this experiment. Each level indicates the number of generations, the total chromosome number, mode of reproduction (A, apomictic; S, sexual) and maize and Tripsacum chromosomal complements (Mz, maize; Td, Tripsacum dactyloides). ' $2 n+n$ ' indicates fertilized unreduced gametes; ' $n+n$ ', fertilized reduced gametes; ' $n+0$ ', nonfertilized reduced gametes. accurate estimates were eventually obtained from root tip squashes observed by phase-contrast microscopy (Jewell \& Islam-Faridi, 1993).

\section{Restriction fragment length polymorphism (RFLP) analysis}

DNA was extracted using a CTAB procedure, digested using the restriction endonuclease EcoRI, electrophoresed and transferred onto uncharged nylon membranes. Extraction, digestion, hybridizations, stringency washes, chemiluminescent detection and exposure were performed according to Hoisington et al. (1994). Maize RFLP clones umc28 and csu68, both known to be linked to apomixis in our materials (Leblanc et al., 1995a), were kindly supplied by the University of Missouri, Columbia.

\section{Results}

The transmission of both the phenotypical expression of apomixis and the chromosomal segment carrying the corresponding genes was analysed in two different generations of backcross derivatives, $\mathrm{BC}_{2}$ and $\mathrm{BC}_{4}$. Some of the data on chromosome numbers and mode of reproduction for these materials have been published elsewhere (Leblanc, 1995; Leblanc et al., 1996). The relevant information is summarized in Fig. 1 and Table 1.

\section{Cosegregation of apomixis and RFLP markers in the $\mathrm{BC}_{2}$ generation}

Seventy-five out of 218 38-chromosome $\mathrm{BC}_{2}$ plants that arose through sexual development $(n+n$ offspring) from the $\mathrm{BC}_{1}$ generation were progeny tested by crossing to maize. Because all produced exclusively $n+n$ offspring (Table 2), they were all

Table 1 Plant materials. Modes of reproduction and chromosome numbers in the various maize-Tripsacum backcross derivatives used in the study

\begin{tabular}{lcc}
\hline Generations & $\mathrm{BC}_{1}{ }^{1}$ & $\mathrm{BC}_{3}{ }^{1,2}$ \\
\hline Chromosome no. & 56 & 38 \\
& $(20 \mathrm{Mz}+36 \mathrm{Td})$ & $(20 \mathrm{Mz}+18 \mathrm{Td})$ \\
Progenies analysed & 6200 & $\mathrm{c} .35000$ \\
Total no. of $n+n$ offspring & 218 & 49 \\
Apomictic $n+n$ & 0 & \\
Total no. of $n+0$ offspring & 12 & \\
Apomictic $n+0$ & 5 & 49 \\
Total & 235 & \\
\hline
\end{tabular}

Sources: ${ }^{1}$ Leblanc, 1995; ${ }^{2}$ Leblanc et al., 1996.

(C) The Genetical Society of Great Britain, Heredity, 80, 40-47. 
Table 2 Determination of mode of reproduction through progeny testing of the various generations of maize-Tripsacum hybrid derivatives

\begin{tabular}{lcccc}
\hline & $\begin{array}{c}\mathrm{BC}_{1}-56 \\
(20 \mathrm{Mz}+36 \mathrm{Td})\end{array}$ & $\begin{array}{c}\mathrm{BC}_{2}-28 \\
(10 \mathrm{Mz}+18 \mathrm{Td})\end{array}$ & $\begin{array}{c}\mathrm{BC}_{2}-38 \\
(20 \mathrm{Mz}+18 \mathrm{Td})\end{array}$ & $\begin{array}{c}\mathrm{BC}_{3}-38 \\
(20 \mathrm{Mz}+18 \mathrm{Td})\end{array}$ \\
\hline No. of progenies & 6200 & 128 & 75 & c. 35000 \\
$2 n+0$ offspring & $80 \%$ & $84 \%$ & - & $90 \%$ \\
$2 n+n$ offspring & $16 \%$ & $16 \%$ & - & $9 \%$ \\
$n+n$ offspring & $3 \%$ & - & $100 \%$ & $0.6 \%$ \\
$n+0$ offspring & $0.2 \%$ & - & - & - \\
$\mathrm{MR}$ & $\mathrm{A}^{*}$ & $\mathrm{~A}^{*}$ & $\mathrm{~S}$ & $\mathrm{~A}$ \\
\hline
\end{tabular}

The proportions of the four types of offspring derived from the original genotypes at the different BC levels are given. *Also analysed using cytology. Mz, maize chromosomes; Td, Tripsacum chromosomes; MR, mode of reproduction

(A, apomictic; S, sexual).

classified as sexual. Out of 12 28-chromosome $\mathrm{BC}_{2}$ dihaploid plants $(n+0$ offspring), five were femalefertile. They were progeny and cytologically tested as described by Leblanc et al. (1996) and were classified as apomicts. The remaining seven $\mathrm{BC}_{2}$ dihaploid plants were sterile, but one could be analysed for callose deposition during megasporogenesis and appeared to be sexual. Given this observation and the high female fertility that characterized the apomictic dihaploid $\mathrm{BC}_{2}$ plants, it could be assumed that all seven sterile dihaploids were probably sexual.

At the phenotypical level, a strong segregation distortion was therefore observed in the $\mathrm{BC}_{2}$ plants, with most plants (the 38-chromosome $\mathrm{BC}_{2}$ plants) being sexual and only rare $\mathrm{BC}_{2}$ dihaploids (28 chromosome $n+0$ offspring) being apomictic. Taking into account all the $\mathrm{BC}_{2}$ plants that could be analysed, sexuality and apomixis segregated in a ratio of $16: 1$.

Because the $\mathrm{BC}_{1}(20 \mathrm{M}+36 \mathrm{Td})$ parent was diploid for the Tripsacum chromosomes, this material was considered suitable for investigating the possible mechanisms of apomixis elimination when transmitted in the simplex condition. RFLP genotypes were obtained for the original parents, the unique apomictic $\mathrm{BC}_{1}$ genotype, 51 out of the 75 sexual 38-chromosome $\mathrm{BC}_{2}$ plants and six dihaploid 28-chromosome plants, including the five apomictic ones, and the proven sexual plant.

Restricted DNAs were probed with clones csu68 and umc28, both of which reveal alleles linked to apomixis. The diagnostic bands for modes of reproduction cosegregated with the phenotypical expression of apomixis. For example, in the blot shown in Fig. 2, apomictic and sexual plants can be identified

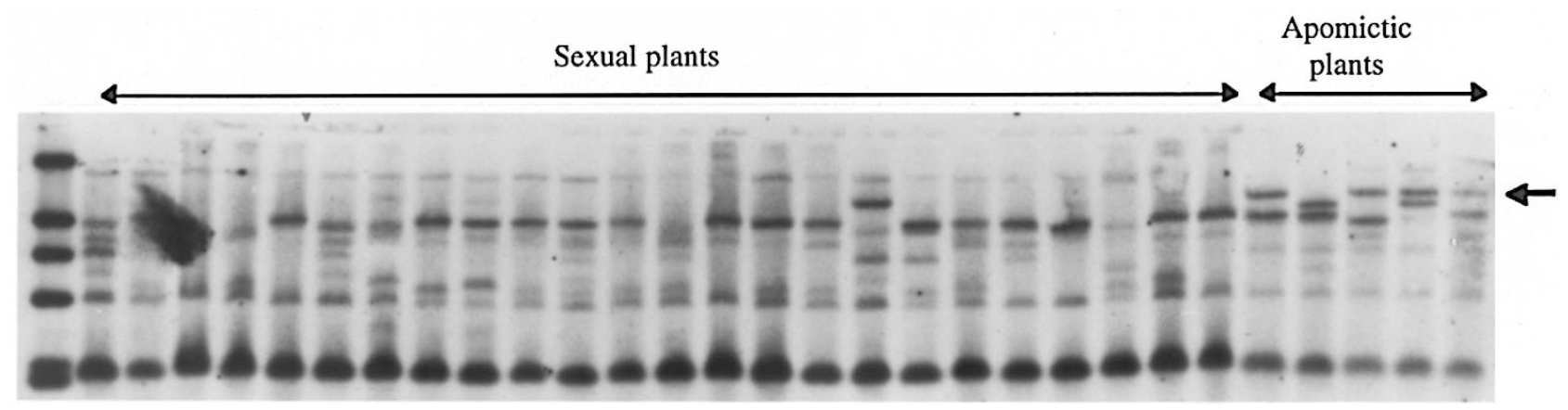

Fig. 2 Segregation of the chromosome segment controlling apomixis as revealed by RFLPs. Southern blot of a subset of both apomictic and sexual $\mathrm{BC}_{2}$ plants derived from maize-Tripsacum hybrids, restricted using endonuclease EcoRI, and hybridized with csu68, a probe linked with apomixis. The arrow indicates the segment cosegregating with the apomictic mode of reproduction.

(c) The Genetical Society of Great Britain, Heredity, 80, 40-47. 
based on the inheritance of the diagnostic RFLP, which disappears from the sexual $\mathrm{BC}_{2}$ plants, whereas it is conserved in the rare apomictic $\mathrm{BC}_{2} \mathrm{~s}$. Two exceptions must be noted, corresponding to putative recombinant plants. The proportion of such recombinant plants (two out of 57 plants) is consistent with the genetic distance between the marker and the trait (Grimanelli et al., 1997). Finally, note that the sexual $\mathrm{BC}_{2}$ dihaploid genotype was confirmed by RFLP analysis.

\section{Random transmission of the RFLP markers in the $\mathrm{BC}_{4}$ generation}

The second population analysed consisted of $49 \mathrm{BC}_{4}$ plants, obtained as $n+n$ offspring from the apomictic 38-chromosome $\mathrm{BC}_{3}$ generation $(20 \mathrm{Mz}+18 \mathrm{Td})$. No data are available on the mode of reproduction in this material but, given the level of agreement observed previously between molecular and phenotypical data, the marker information was used to deduce the most probable modes of reproduction in the $\mathrm{BC}_{4}$ generation. RFLP genotypes were obtained for all plants. The results are given in Table 3. In contrast to the $\mathrm{BC}_{2}$ generation, in which the transmission of apomixis is heavily biased towards the elimination of the corresponding segment, the marker data fit a random transmission of the chromosomal segment controlling apomixis from the apomictic $\mathrm{BC}_{3}$ plants to its $\mathrm{BC}_{4}$ offspring (Table 3 ). In effect, no significant deviation from a random transmission of the RFLP markers could be detected $\left(\chi_{13}^{2}=0.96 ; P=0.99\right)$. Even though the number of plants studied does not allow a very powerful test, this must be compared with the very strong distortion observed in the $\mathrm{BC}_{2}$ generation.

\section{Discussion}

Nontransmission of apomixis through simplex condition

As shown by Leblanc et al. (1995a), diplospory segregates in a $1: 1$ ratio in maize-Tripsacum $\mathrm{F}_{1} \mathrm{~s}$, as expected for a dominant allele. In contrast, a strong distortion of the 1:1 ratio was observed in the $\mathrm{BC}_{2}$ generation, which contradicts the Mendelian factor model. Moreover, whenever transmitted (c. 5 per cent of the $\mathrm{BC}_{2}$ plants), apomixis is functionally

Table 3 Transmission of the apomictic mode of reproduction as revealed by RFLP markers in the $\mathrm{BC}_{4}$ generation derived from maize-Tripsacum hybrids

\begin{tabular}{lcccc}
\hline $\begin{array}{l}\text { No. of } \\
\text { Tripsacum } \\
\text { chromosomes } \\
(c)\end{array}$ & $\begin{array}{c}\text { No. of plants } \\
\text { observed } \\
(n)\end{array}$ & $\begin{array}{c}\text { No. of sexual } \\
\text { genotypes } \neq\end{array}$ & $\begin{array}{c}\text { No. of } \\
\text { apomictic } \\
\text { genotypes }\end{array}$ & $\begin{array}{c}\text { Expected no. } \\
\text { of apomicts } \dagger \\
(=n c / 18)\end{array}$ \\
\hline 1 & 5 & 5 & 0 & 0.3 \\
2 & 4 & 4 & 0 & 0.4 \\
3 & 2 & 2 & 0 & 0.3 \\
4 & 6 & 5 & 1 & 1.3 \\
5 & 1 & 1 & 0 & 0.3 \\
6 & 1 & 1 & 0 & 0.3 \\
7 & 1 & 0 & 1 & 0.4 \\
8 & 7 & 6 & 1 & 3.1 \\
9 & 0 & 0 & 0 & 0 \\
10 & 1 & 0 & 1 & 0.6 \\
11 & 4 & 0 & 4 & 2.4 \\
12 & 4 & 2 & 2 & 2.7 \\
13 & 4 & 1 & 3 & 6.2 \\
14 & 8 & 1 & 7 & 0 \\
15 & 0 & 0 & 0 & 0.9 \\
16 & 1 & 0 & 1 & \\
\hline
\end{tabular}

$\dagger$ Expected number of apomicts under a random transmission hypothesis for the chromosome carrying the apomixis allele, estimated from the probability of transmission of one chromosome, $n c / 18$, where $n$ is the number of plants, $c$ is the number of chromosomes and 18 is the basic chromosome number in Tripsacum.

¥Carrying either sexual or apomictic genotype, as revealed by RFLPs. 
expressed in simplex conditions in maize-Tripsacum dihaploid plants (Leblanc et al., 1996).

Clearly, our results do not fit the allelic ratio hypotheses proposed by Mogie (1988) and Noirot (1993). The ratio of 'apomictic' vs. 'sexual' alleles in the dihaploids $(10 \mathrm{Mz}+18 \mathrm{Td} ; r=0.5)$ and subsequent $\mathrm{BC}_{3}$ plants $(20 \mathrm{Mz}+18 \mathrm{Td} ; \quad r=0.33)$ contradicts Mogie's model, in which apomixis arises when the ratio is more than 0.5 . By the same token, it contradicts the model proposed by Noirot, which postulates that apomixis is not functional when this ratio is more than 0.25 .

Moreover, the RFLP analysis confirmed that the strong segregation distortion favouring sexuality in the $\mathrm{BC}_{2} \mathrm{~S}$ resulted from the elimination of the segment responsible for apomixis. Hence, our results corroborate Nogler's hypothesis (Nogler, 1982) concerning the transmission of apomixis in Ranunculus auricomus: the segment controlling apomixis is usually eliminated when transmitted in the simplex condition rather than not expressed when recovered in diploids.

The exclusion of apomixis probably depends on a trans-active but incompletely penetrant selective system

Nogler (1982) hypothesized, without describing possible mechanisms, that, in $R$. auricomus, the elimination of the apomixis alleles in the simplex condition could be explained by a linked lethal system. According to our data, a similar system may well be acting in Tripsacum. Some details can be added to Nogler's hypothesis by analysing the dihaploid $\mathrm{BC}_{2}$ plants, that is, plants resulting from the rare events of apomixis transmission from reduced $\mathrm{BC}_{1}$ gametes to $\mathrm{BC}_{2}$. Rare crossovers between the gene(s) responsible for apomixis and a putative lethal system provide a possible explanation for the occurrence of such escapes. Alternatively, an incomplete penetrance of this system, resulting in a small proportion of the selectable alleles being transmitted, might be considered. Furthermore, the system may act either in trans or in cis configuration (Fig. 3).

The chromosome segment controlling apomixis in this material has been shown to present a very strong restriction to recombination (Grimanelli et al., 1997). This contradicts the relatively high frequency of dihaploid $\mathrm{BC}_{2} \mathrm{~s}$ (c. 5 per cent). Furthermore, crossovers would result in exclusively apomictic 28-chromosome $\mathrm{BC}_{2}$ escapes (Fig. 3). But at least one sexual plant and, more likely, seven were recovered in the dihaploids. Taken together, the existence of sexuality in those plants and the absence of recombination in that segment make recombination an unlikely explanation for escapes.

If the lethal system were cis-active but incompletely penetrant, only sexual plants would have been recovered in the $\mathrm{BC}_{4}$ generation (Fig. 3), which is not what we observed. By contrast, an incompletely penetrant trans-active system would be selfeliminating; thus, the segment controlling apomixis would randomly segregate in the $\mathrm{BC}_{4}$ plants, as observed (Table 3). Hence, the more parsimonious hypothesis is that of a trans-active but incompletely penetrant system. Our observations are consistent with the hypothesis of a lethal factor that acts at least maternally to cause the death of the gametes inheriting the control of apomixis in the simplex condition. Such a factor would be responsible for the strong segregation distortion observed in our experiment and for the absence of apomixis in diploids.

Transmission ratio distortion systems are defined as mechanisms resulting in a significant departure from Mendelian inheritance, regardless of their bases (Crow, 1991). When caused by meiotic drive, the mechanisms of meiosis cause one of the allelic alternatives to be transmitted in excess to the progeny. Meiotic drive systems causing transmission ratio distortion have been described in many organisms (Lyttle, 1991), and are thought to be widespread in plants (Rick, 1965; Sano, 1990). A meiotic drive system actively promotes the elimination of the gametes not carrying it, therefore enhancing its own transmission to the progeny. Interestingly, the only known example acting as an egg eliminator in plants has been observed in maize-Tripsacum hybrids (Maguire, 1963), in which an extra chromosome from Tripsacum was transmitted with a very high frequency to the progenies through the eggs. No data are available, however, to connect this observation to the chromosome carrying the control of apomixis.

Only a few of the reported cases of meiotic drive systems have been subjected to intensive characterization (reviewed by Lyttle, 1991). They are usually genetically complex and typically involve the presence of a target locus in cis configuration, a trans-acting distorter locus, an incompletely penetrant expression and eventual modifier loci. The integrity of this multilocus system is frequently conserved through the establishment of chromosome rearrangements limiting the extent of recombination between its components. Most of these features are observed in the Tripsacum distortion system: limited recombination occurs on that segment (Grimanelli et 
al., 1997), the system would probably be trans-acting and incomplete penetrance can also be assumed.

\section{Evolutionary significance of the relationship between apomixis and polyploidy}

Models (Pernès, 1972; Maynard Smith, 1978; Marshall \& Brown, 1981) show that, under a single dominant gene hypothesis and at the same level of ploidy, obligate apomixis rapidly invades populations. As a result, sexuality would disappear. The predominance of apomixis in polyploid apomictic populations strongly supports the models. Therefore, apomixis has often been considered as a 'blind alley of evolution' (Darlington, 1939) with a restricted evolutionary potential. However, apomictic populations are always characterized by a remarkable level of genetic diversity, hardly compatible with the former views (Asker \& Jerling, 1992). Two mechanisms have been suggested to explain this diversity. First, as shown in Erigeron populations (Noyes \& Soltis,
1996), the facultative nature of apomixis permits hybridizations between apomictic individuals, and thus the creation of new apomictic genotypes. Moreover, extensive gene exchanges between the diploid sexuals and the polyploid apomicts serves as a source of novel genotypical variation (de Wet, 1968; Savidan \& Pernès, 1982; Menken et al., 1995); gene flow between both ploidy levels, whenever they coexist, might represent the major source of new genetic variation in apomicts. Recombination and selection occur at the diploid level, generating new apomictic genotypes after hybridization that may eventually be fitter than the former in a changing environment. The protection of a purely sexual and highly variable diploid gene pool against apomixis is therefore a condition for the maintenance of the evolutionary potential of the agamic complex as a whole. Here, we report on a probable mechanism for achieving such protection, based on a transmission ratio distortion linked to the segment controlling apomixis.

\section{Hypothesis 1: trans-acting system}
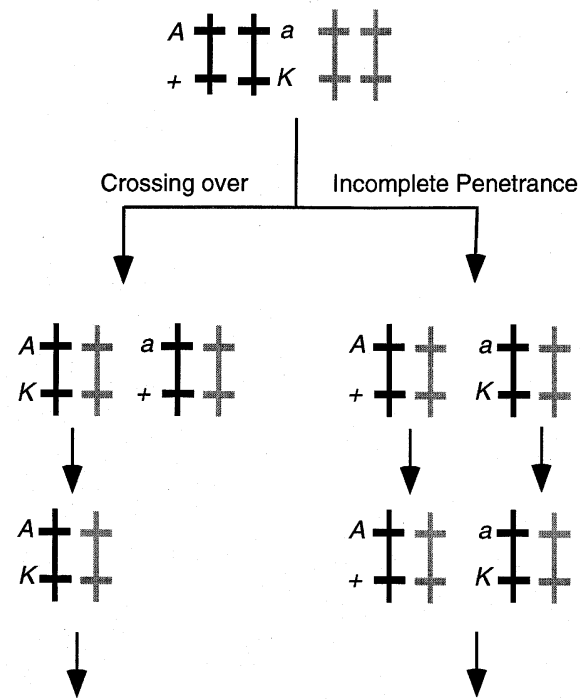

Only apomictic progenies

$K$ conserved in apomictic plants

Only apomicts in the $\mathrm{BC}_{4}$ plants

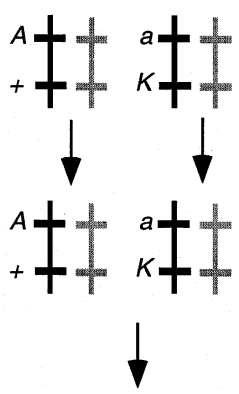
progenies

\section{$K$ eliminated from} apomictic plants

Random segregation of apomixis in the $\mathrm{BC}_{4} \mathrm{~S}$
Segregating

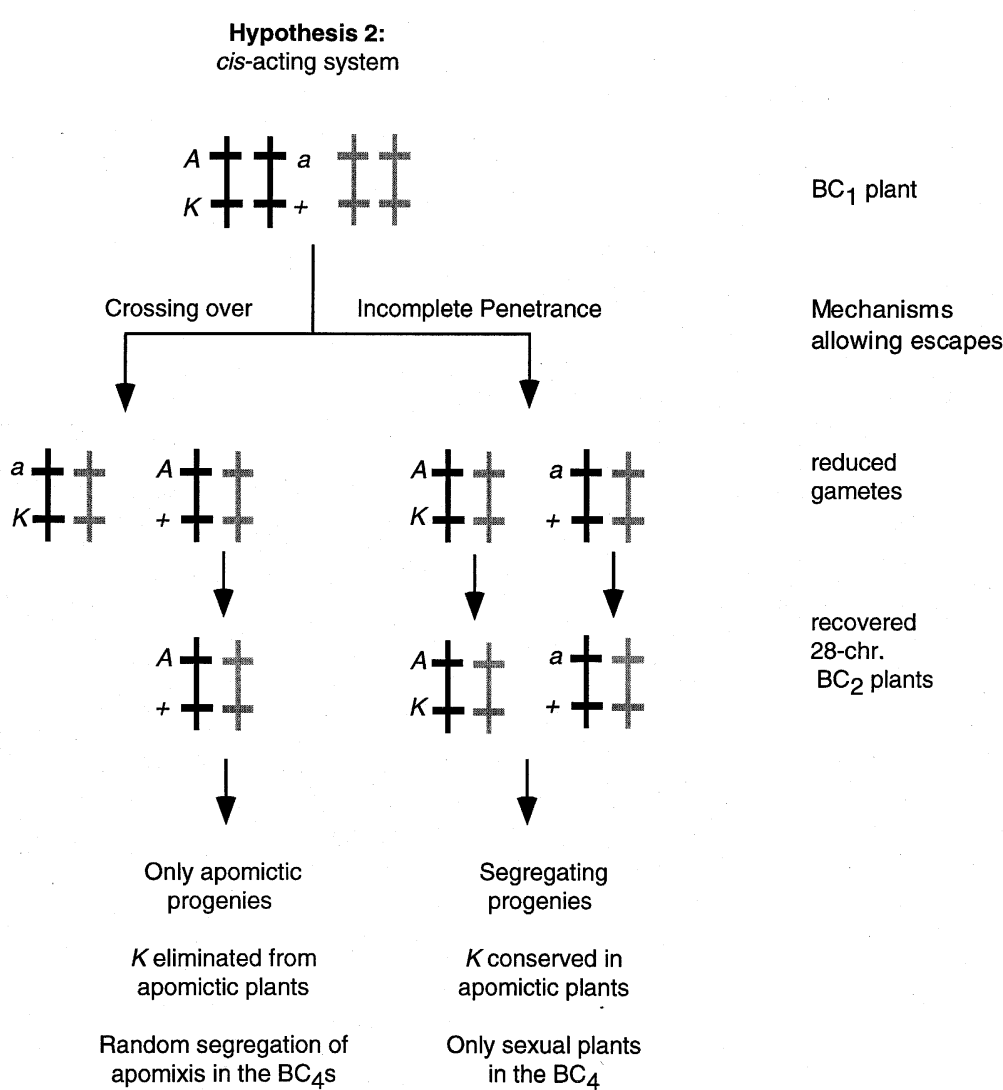

Hypothesis 2:

cis-acting system

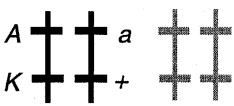

$\mathrm{BC}_{1}$ plant

Mechanisms allowing escapes

reduced $1+10$ in the $\mathrm{BC}_{4}$

Fig. 3 Possible configurations for a lethal system linked with apomixis and hypotheses for escapes. $K$, distortion transmission factor; $A$, apomixis allele; $a$, wild allele at the apomixis locus. Chromosomes in black are from Tripsacum and grey ones are from maize. 
The question remains of the generalization of this model to the male gametes. Furthermore, it would be of interest to test the validity of this hypothesis in other apomictic species. The relationship between apomixis and polyploidy is common to almost all apomicts, and similar transmission distortions should be expected in most cases. It is conceivable, however, that different mechanisms might be acting with the same consequences. Hence, the models proposed by Mogie (1988) and Noirot (1993), even though they do not seem to apply in Tripsacum, might remain valid in other situations.

\section{References}

ASKer, S. AND Jerling, L. 1992. Apomixis in Plants. CRC Press, Boca Raton, FL.

BABCOCK, E. B. AND STEBBINS, G. L. 1938. The American species of Crepis: their interrelationships and distribution as affected by polyploidy and apomixis. Publ. Carnegie Inst. Washington, 504, 1-119.

CROW, J. F. 1991. Why is Mendelian segregation so exact? BioEssays, 13, 305-312.

DARLington, C. D. 1939. The Evolution of Genetic Systems. Cambridge University Press, Cambridge.

DE WET, J. M. J. 1968. Diploid-tetraploid-haploid cycles and the origin of variability in Dichanthium agamospecies. Evolution, 22, 394-397.

GALBRAITH, D. W., HARKINS, K. R., MADDOX, J. M., AYRES, N. M., SHARMA, D. P. AND FIROOZABADY, E. 1983. Rapid flow cytometric analysis of the cell cycle in intact plant tissues. Science, 220, 1049-1051.

Grimanelli, D., Leblanc, O., ESPinOSA, E., PEROtTI, E., GONZÁLEZ DE LEÓN, D. AND SAVIDAN, Y. 1997. Mapping diplosporous apomixis in tetraploid Tripsacum: one gene or several genes? Heredity, 80, 33-39.

HARLAN, J. R. AND DE WET, J. M. J. 1975. On O. Winge and a prayer: the origins of polyploidy. Bot. Rev., 41, 361-390.

HOISINGTON, D., KHAIRALLAH, M. AND GONZÁLEZ-DE-LEÓN, D. 1994. Laboratory Protocols: CIMMYT Applied Molecular Genetics Laboratory, 2nd edn. CIMMYT, México DF.

JEWELL, D. AND ISLAM-FARIDI, N. 1993. A technique for somatic chromosome preparation and C-banding in maize. In: Freeling, W. and Walbot, V. (eds) The Maize Handbook, pp. 484-492. Springer Verlag, New York.

KONDRASHOV, A. s. 1993. Classification of hypotheses on the advantage of amphimixis. J. Hered., 84, 372-387.

LEBLANC, O. 1995. Modes de reproduction dans le complexe agamique des Tripsacum, et analyse d'hybrides maïsTripsacum en vue du transfert de l'apomixie chez le maïs. Ph.D. Dissertation, Institut National Agronomique Paris-Grignon, Paris.

LEBLANC, O., GRIMANELLI, D., GONZALÉZ DE LÉON, D. AND SAVIDAN, Y. 1995a. Detection of the apomictic mode of reproduction in maize-Tripsacum hybrids using maize RFLP markers. Theor. Appl. Genet., 90, 1198-1203.

LEBLANC, O., PEEL, M. D., CARMAN, J. G. AND SAVIDAN, Y. 1995b. Megasporogenesis and megagametogenesis in several Tripsacum species (Poaceae). Am. J. Bot., 82, $57-63$.

LEBLANC, O., GRIMANELLI, D., ISLAM-FARIDI, N., BERTHAUD, J. AND SAVIDAN, Y. 1996. Reproductive behaviour in maize-Tripsacum polyhaploid plants; implications for the transfer of apomixis into maize. J. Hered., 87, 108-111.

lyttle, t. w. 1991. Segregation distorters. Ann. Rev. Genet., 25, 511-557.

MAGUIRE, M. P. 1963. High transmission frequency of a Tripsacum chromosome in corn. Genetics, 48, 1185-1194.

MARSHALL, D. R. AND BROWN, A. H. D. 1981. The evolution of apomixis. Heredity, 47, 1-15.

MAYnard Smith, J. 1978. The Evolution of Sex. Cambridge University Press, Cambridge.

MENKEN, S. B. J., SMIT, E. AND DEN NIJS, J. C. M. 1995. Genetical population structure in plants. Gene flow between diploid sexual and tetraploid asexual dandelions (Taraxacum section Ruderalia). Evolution, 49, 1108-1118.

MOGIE, M. 1988. A model for the evolution and control of generative apomixis. Biol. J. Linn. Soc., 35, 127-153.

NOGLER, G. A. 1982. How to obtain diploid apomictic Ranunculus auricomus plants not found in the wild state. Bot. Helvet., 92, 13-22.

NOGLER, G. A. 1984a. Gametophytic apomixis. In: Johri, B. M. (ed.) Embryology of Angiosperms, pp. 475-518. Springer Verlag, Berlin.

NOGLER, G. A. 1984b. Genetics of apospory in apomictic Ranunculus auricomus V. Conclusions. Bot. Helvet., 94, 411-422.

NOIROT, M. 1993. Allelic ratios and sterility in the agamic complex of the Maximeae (Panicoideae): evolutionary role of the residual sexuality. J. Evol. Biol., 6, 95-101.

NOYES, R. D. AND SOLTIS, D. E. 1996. Genotypic variation in agamospermous Erigeron compositus (Asteraceae). Am. J. Bot., 83, 1292-1303.

PERNÈs, J. 1972. Organisation évolutive d'un complexe agamique: la section des Maximae du genre Panicum (Graminées). Ph.D. Dissertation, University of Paris XI.

RICK, C. M. 1965. Abortion of male and female gametes in the tomato determined by allelic interaction. Genetics, 53, 85-96.

SANO, Y. 1990. The genic nature of gamete eliminator in rice. Genetics, 125, 183-191.

SAVIDAN, y. 1982. Nature et hérédité de l'apomixie chez Panicum maximum Jacq. Ph.D. Dissertation, University of Paris XI.

SAVIDAN, Y. AND PERNÈs, J. 1982. Diploid-tetraploiddihaploid cycles and the evolution of Panicum maximum Jacq. Evolution, 36, 596-600. 